\title{
2 - Indicadores em saúde e do núcleo de segurança do paciente
}

\author{
Celsa Raquel Villaverde Melgarejo \\ Patricia de Carvalho Mastroianni \\ Fabiana Rossi Varallo
}

\section{SciELO Books / SciELO Livros / SciELO Libros}

MELGAREJO, C. R. V., MASTROIANNI, P. C., and VARALLO, F. R. Indicadores em saúde e do núcleo de segurança do paciente. In: Promoção da cultura de notificação de incidentes em saúde [online]. São Paulo: Editora UNESP, 2019, pp. 19-24. ISBN: ISBN: 978-85-9546-337-0. https://doi.org/10.7476/9788595463370.0004.

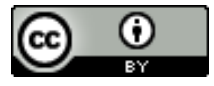

All the contents of this work, except where otherwise noted, is licensed under a Creative Commons Attribution 4.0 International license.

Todo o conteúdo deste trabalho, exceto quando houver ressalva, é publicado sob a licença Creative Commons Atribição 4.0.

Todo el contenido de esta obra, excepto donde se indique lo contrario, está bajo licencia de la licencia Creative Commons Reconocimento 4.0. 


\section{2 \\ INDICADORES EM SAÚDE E DO NÚCLEO DE SEGURANÇA DO PACIENTE}

A identificação de fragilidades e o desenvolvimento de estratégias para a melhoria no desempenho da assistência à saúde em busca da qualidade é um desafio a ser superado por várias instituições atualmente. Na saúde, a qualidade é entendida como um conjunto de atributos com nível de excelência que permita ao paciente e a seus familiares alto grau de satisfação pelo uso de recursos eficientes (Rossaneis et al., 2014).

A busca pela melhoria na qualidade de atendimento vem sendo incorporada na rotina dos profissionais e gestores de unidades de saúde. O controle da qualidade da assistência prestada é medido a partir de parâmetros que possam mensurar a evolução de efetividade ao longo do tempo. Lança-se mão do uso de indicadores como ferramentas utilizadas para reconhecer uma situação existente e avaliar a sua mudança com passar do tempo, por meio da proposta de ações de melhoria e de sua execução (Vieira; Kurcgant, 2010).

São inúmeras as definições de indicadores da saúde e, no geral, todas convergem como um atributo ou variável capaz de representar algo que se quer medir em um sistema de saúde. Não são medidas de bom ou mau desempenho mas podem sinalizar fragilidades e oportunidades para a melhoria da qualidade (Rede, 2008). Seus componentes são numéricos e estão associados a uma relação 
matemática entre o referencial e o comparativo (numerador/denominador) (Vieira; Detoni; Braum, 2006).

Os indicadores utilizados como instrumentos de monitoramento para a segurança do paciente devem ser confiáveis a ponto de reproduzir os mesmos resultados quando aplicados em condições similares; devem ser válidos, ou seja, ter a capacidade de medir aquilo que realmente se pretende; e devem ser apropriados no que tange à viabilidade, relevância e custo-efetividade, para identificar os riscos e orientar centradamente a tomada de decisão (Gama et al., 2016).

Quanto aos tipos de indicadores, incluem-se os i) de estrutura, voltados para avaliação de recursos físicos, ambientais, humanos (quantidade e qualificação dos profissionais de saúde), materiais e financeiros; ii) de processos, que avaliam diretamente os cuidados prestados ao paciente, oriundos de técnicas operacionais por meio da utilização de conhecimentos científicos, além da relação interpessoal entre profissional e paciente; iii) de resultado, no qual os efeitos dos cuidados prestados ao paciente/população são avaliados além da mensuração do grau de satisfação do usuário com relação ao serviço de saúde (Donabedien, 1988).

Estes últimos são os mais utilizados com enfoque na segurança do paciente e estão embasados em eventos denominados never events, propostos pela The Joint Commission, e também utilizados pela Anvisa no Brasil (Austin; Pronovost, 2015; Gouvêa; Travassos, 2010). Essas instituições desenvolveram indicadores que visam a ausência de incidentes relacionados à saúde.

A terminologia de never events, que certos indicadores da saúde recebem, refere-se a incidentes graves que são totalmente evitáveis e que resultam em morte ou danos graves para o paciente (The Canadian Patient Safety Institute, 2015). Em 2002, o The National Quality Forum (NQF), uma organização sem fins lucrativos que visa a melhoria da qualidade dos cuidados em serviços de saúde nos Estados Unidos, publicou seu primeiro relatório, no qual foram listados 27 eventos considerados sérios e que nunca deveriam acontecer nas instituições de saúde. 
Esses erros passíveis de notificações incluem falhas óbvias e inaceitáveis, como, dentre outras, realizar cirurgia em parte incorreta do corpo. Em 2006, o NQF atualizou essa lista e atribuiu mais um item (Quadro 1), que se encontra distribuído em seis categorias de incidentes, quais sejam, procedimentos cirúrgicos, incidentes relacionados ao uso de produtos e serviços, proteção do paciente, incidentes ocorridos nos cuidados gerais do paciente, ambientais e penais, totalizando assim 28 incidentes classificados como never events (NQF, 2011; Lembitz; Clarke, 2009).

O Serviço Nacional de Saúde britânico (National Health Service - NHS) também adotou e adaptou a lista dos never events do NQF, e em sua mais recente atualização (2015/2016) constam 14 eventos, classificados em cirurgia, medicamentos, saúde mental e atenção de cuidados gerais, entre outros (NHS, 2015).

\section{Quadro 1 - Incidentes classificados como never events, NQF.}

\section{Never events em procedimentos cirúrgicos}

Procedimento realizado em paciente errado.

Procedimento realizado no lado errado do corpo.

Procedimento realizado em local errado.

Óbito intraoperatório ou imediatamente pós-operatório em paciente ASA Classe 1.

Retenção não intencional de corpo estranho em paciente após a cirurgia.

Never events relacionados à produtos e serviços

Óbito ou lesão grave associados ao uso de medicamentos, dispositivos ou produtos biológicos contaminados fornecidos pela instituição de saúde.

Óbito ou lesão grave associada ao uso de dispositivo no cuidado do paciente em que o dispositivo é usado ou funciona de modo diferente ao pretendido.

Óbito ou lesão grave associados à embolia do ar intravascular durante a prestação de assistência.

Never events relacionados à proteção do paciente

Óbito ou lesão grave associados à fuga do paciente.

Suicídio ou tentativa de suicídio pelo paciente, resultando em deficiência ou incapacidade grave durante a assistência no serviço de saúde.

\section{Never events no gerenciamento de cuidados ao paciente}

Óbito ou lesão grave associados a erros de medicação (medicamento errado, dose incorreta, paciente errado, preparo incorreto, via de administração errada). 
Óbito ou lesão grave associados à reação hemolítica em razão da administração de sangue incompatível com sistema ABO/HLA ou hemoderivados.

Óbito ou lesão grave associados ao trabalho de parto ou à parto em gravidez de baixo risco.

Óbito ou lesão grave associados à hipoglicemia $(<60 \mathrm{mg} / \mathrm{dL})$ durante a prestação de cuidados.

Óbito ou lesão grave associados à incapacidade de identificar e tratar a hiperbilirrubinemia em neonatos.

Lesão por pressão estádios 3 ou 4 adquiridas no serviço de saúde.

Óbito ou lesão grave em decorrência de terapia manipuladora da coluna vertebral.

Inseminação artificial com esperma do doador errado ou com óvulo errado.

\section{Never events ambientais}

Óbito ou lesão grave associados à choque elétrico durante cuidados à saúde.

Administração de gás errado ou contaminado, quando designada a administração de oxigênio ou outros gases medicinais.

Óbito ou lesão grave associados à queimadura derivada de qualquer fonte durante assistência no serviço de saúde.

Óbito ou lesão grave associados à queda do paciente durante a estadia em serviços de saúde.

Óbito ou lesão grave associados ao uso de contenção física ou grades do leito durante a assistência no serviço de saúde.

\section{Never events penais}

Qualquer instância relacionada ao cuidado providenciado por alguém que não seja da área da saúde, como médicos, enfermeiros, farmacêuticos ou outro profissional licenciado na área.

Sequestro de paciente de qualquer idade.

Abuso sexual ao paciente.

Óbito ou lesão grave de paciente ou profissional de saúde resultante de ataque físico ocorrido no serviço de saúde.

Fonte: Adaptado de NQF (2011).

No Brasil, além da lista do NQF (Quadro 1), ainda são considerados never events os seguintes incidentes:

- óbito ou lesão grave resultante de perda irrecuperável de amostra biológica insubstituível;

- alta ou liberação de paciente de qualquer idade que seja incapaz de tomar decisões para tal ou designar alta para outra pessoa; 
- óbito ou lesão grave de paciente resultante da falha no seguimento ou na comunicação de resultados de exames radiológicos;

- óbito ou lesão grave de paciente ou profissional associados à introdução de objeto metálico em áreas de ressonância magnética.

Segundo critérios estabelecidos no plano de Segurança do Paciente, casos de óbitos, assim como os never events, devem ser notificados à Anvisa em um prazo máximo de 72 horas e imediatamente investigados pelo Serviço Nacional de Vigilância Sanitária (SNVS) (Anvisa, 2016).

Dessa forma, as notificações de incidentes realizadas pelas instituições de saúde poderão gerar indicadores para traçar planos e medidas pontuais, propondo ações de minimização de riscos a fim de reduzir a reincidência de falhas (Bezerra et al., 2009).

Com o intuito de reforçar os incidentes do tipo never events proposto pelo NQF, que cita o uso de medicamentos em sua lista, também é importante destacar o uso e a prescrição de medicamentos potencialmente perigosos (MPP). Esses medicamentos representam maior risco de causar danos sérios e permanentes, além de levar o paciente a óbito em decorrência da falha no processo de sua utilização. Incluem-se nessa classe, uma gama diversificada de medicamentos, como água estéril para inalação (volume de 100 mL ou maior); cloreto de potássio concentrado injetável; cloreto de sódio hipertônico (concentração > a 0,9\%); epinefrina subcutânea; fosfato de potássio injetável; glicose hipertônica (concentração maior ou igual a 20\%); metotrexato de uso oral não oncológico; nitroprussiato de sódio injetável; oxitocina endovenosa; prometazina endovenosa; sulfato de magnésio injetável; tintura de ópio; vasopressina injetável, dentre outros de uso hospitalar (Quadro 2) (ISMP, 2011). 
Quadro 2-Medicamentos potencialmente perigosos de uso hospitalar, ISMP.

Agonistas adrenérgicos endovenoso (ex.: epinefrina, fenilefrina, norepinefrina).

Analgésicos opioides endovenosos, transdérmicos e de uso oral (formulação de liberação imediata ou prolongada).

Anestésicos gerais, inalatórios e endovenosos (ex.: propofol, cetamina).

Antagonistas adrenérgicos endovenosos (ex.: propanolol, metropolol).

Antiarrítmicos endovenosos (ex.: lidocaína, amiodarona).

Antitrombóticos.

Anticoagulantes: varfarina, heparinas não fracionadas e de baixo peso molecular (ex.: enoxaparina, nadroparina).

Inibidores do Fator Xa: rivaroxabana, apixabana.

Inibidores diretos da trombina: lepirudina.

Trombolíticos: tenecteplase.

Inibidores da glicoproteína IIb/IIIa: tirofibana.

Bloqueadores neuromusculares (suxametônio, pancurônio, vecurônio).

Contrastes radiológicos endovenosos.

Hipoglicemiantes orais.

Ionotrópicos endovenosos.

Insulina subcutânea e endovenosa (em todas as formas de apresentações ).

Medicamentos administrados por via epidural ou intratecal.

Medicamentos na forma lipossomal e seus correspondentes na forma convencional.

Quimioterápicos de uso oral e parenteral.

Sedativos de uso oral de ação moderada para criança.

Sedativos endovenosos de ação moderada.

Soluções cardioplégicas.

Soluções para diálise.

Soluções de nutrição parenteral.

Fonte: ISMP (2011).

Os indicadores podem fazer parte da política de gerenciamento de riscos de diversas instituições de saúde e tem como principal objetivo identificar, monitorar e minimizar incidentes ou circunstâncias de riscos que possam causar dano ao paciente, além de traçar planos de ações preventivos. 